\title{
OS ARREDORES DAS CIDADES ROMANAS DE PORTUGAL
}

\author{
POR \\ JORGE DE ALARCÃO \\ Universidade de Coimbra
}

\begin{abstract}
SUMÁRIO
$\mathrm{O}$ autor distinguiu, em anteriores trabalhos, três níveis de aglomerados populacionais —capitais de civitates, vici e castella/aldeias - e três níveis de estabelecimentos ruraisvillae, granjas e casais. Neste artigo examina os arredores das cidades romanas de Portugal e distingue três tipos de paisagem: uma composta por granjas e casais, eventualmen te algumas villae; outra, por aldeias, mais ou menos distantes umas das outras; e uma terceira, composta de villae num território centuriado.
\end{abstract}

\section{SUMMARY}

The author has considered in previous papers three levels of Roman urban settlements: capital towns, vici and castella (Romanized hill-forts or villages; and «casais» or very small farm-houses). In the present paper, he considers the landscape on the outskirts of four Roman capital towns of Portugal and distinguishes three different landscapes: the first with middle and small farms, sometimes, a villa; the second, with villages around the town, at some distance; finally, the villae in a centuriated landscape.

Não existiu, no território actualmente português, sob o domínio romano, um modelo único de distribuição populacional e de propriedade do solo nos arredores das cidades. Nalguns casos vemos, em torno da cidade, múltiplos casais e granjas e, eventualmente, algumas villae. Noutros, os arredores da cidade, cartografados os vestígios arqueológicos, parecem vazios e, a alguma distância, surgem aldeias. Noutros casos ainda, houve centuriação e as villae surgem logo na periferia das cidades.

Pretendemos, neste artigo, comentar os três tipos de distribuição populacional. Antes de analisarmos os casos, exporemos brevemente, por necessário para a compreensão do nosso texto, em que sentido utilizamos os nomes de aldeia, granja e casal.

Distinguimos três níveis de aglomerados populacionais: as cidades capitais de civitates, os vici e, num terceiro nível, as aldeias e os castella. Estes últimos são os antigos castros da Idade do Ferro que não foram abandonados. Na parte oriental de Trásos-Montes, Sande Lemos (1993) identificou 246 povoados castrejos, 75 dos quais apresentam vestí- gios de romanização. O índice de abandono dos povoados parece considerável; não obstante, cerca de $30 \%$ mantiveram-se sob o domínio romano (até quando?). Na bacia do curso médio do rio Cávado, isto é, na região de Braga, Manuela Martins (1990) identificou 45 castros, dos quais 16 foram seguramente romanizados e 3 possivelmente romanizados. $\mathrm{O}$ índice de romanização dos castros é aqui, pelo menos, de $35 \%$.

Por aldeia, que incluímos no mesmo nível dos castella, designamos os pequenos povoados de origem romana, sem fortificações e estabelecidos em cotas baixas, para os quais presumimos uma população de 10 a 15 fogos, no máximo. Não há, porém, nenhuma escavação de aldeia romana em Portugal, pelo que o nosso cômputo carece de comprovação; é apenas uma suspeita, baseada no que supomos ter sido a dimensão média das aldeias na Alta Idade Média.

Similarmente, no povoamento rural isolado distinguimos três níveis: a villa, a granja e o casal. Por villa entendemos habitação com todo o conforto urbano (designadamente mosaicos e termas), sede de exploração agrária que andaria pelos 200 hectares. Por granja entendemos a casa sem esses urbana ornamenta a que se refere Varrão, presidindo a exploração agrária que poderia oscilar entre 10 e 50 hectares. Por casal designamos modesta exploração da ordem dos 2 ou 3 a 10 hectares. Obviamente, tornase por vezes difícil, sem escavação, distinguir uma villa, de uma granja, ou uma granja, de um casal. Consideramos que se devem tomar por casais os sítios com vestígios superficiais dispersos por uma área até $1.000 \mathrm{~m}^{2}$, con maior frequência entre $400 \mathrm{e}$ $600 \mathrm{~m}^{2}$. As granjas aprensentarão uma área de dispersão de vestígios entre 1.000 e $5.000 \mathrm{~m}^{2}$ e as $v i$ llae, uma área superior a $5.000 \mathrm{~m}^{2}$. A presença, à superfície, de sigillata ou apenas de cerâmica comum, é um critério suplementar que, conjugado com a área de dispersão superficial dos achados, ajudará a classificar as estações previamente à sua escavação. Estes critérios foram por nós mais desenvolvidamente expostos noutro lugar (Alarcão, 1998). 


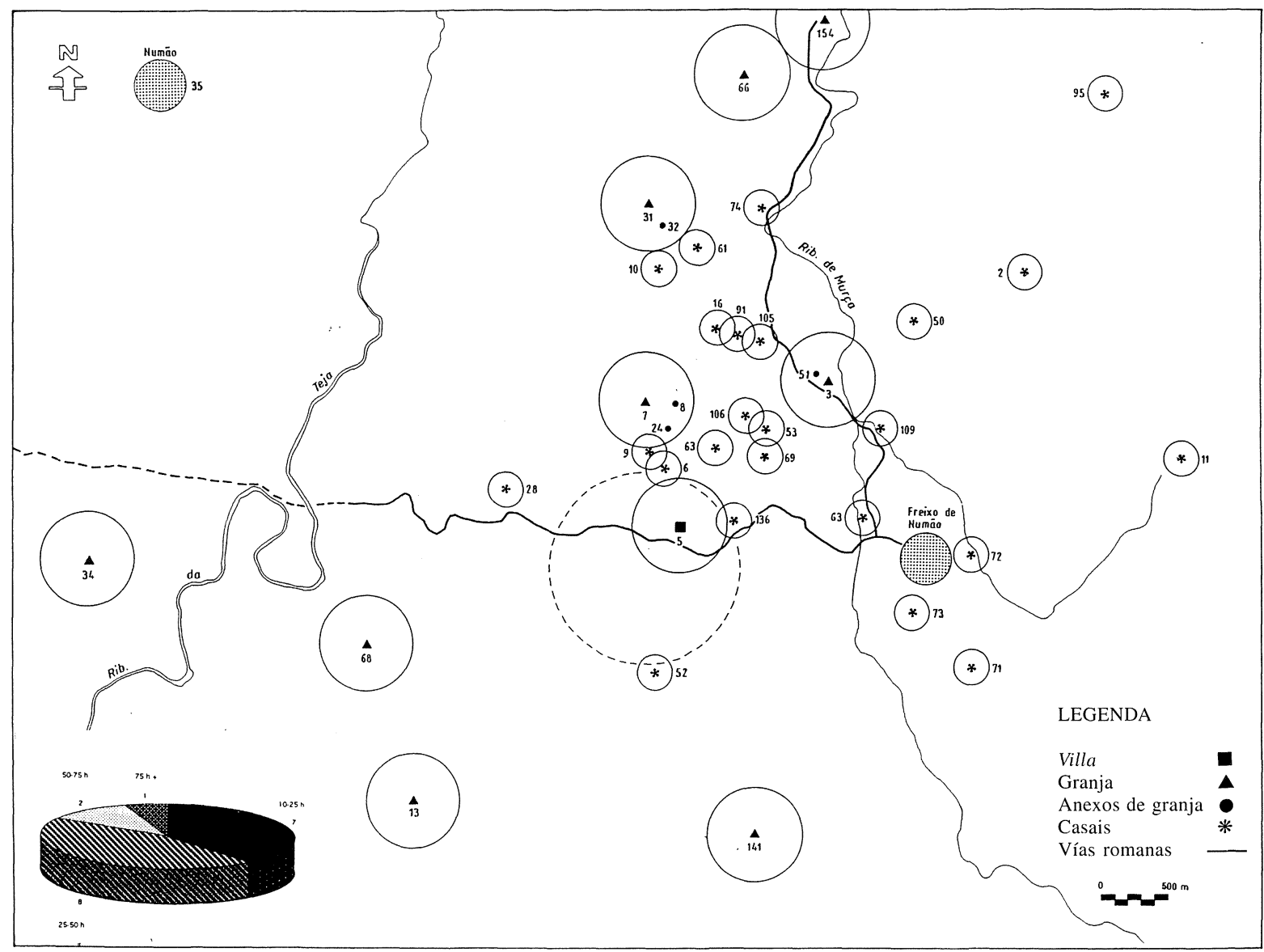

Fig. 1.-Arredores da provável Meidobriga (Freixo de Numão).

\section{O CASO DE FREIXO DE NUMÃO (Fig. 1)}

A vila actual de Freixo de Numão situa-se no território dos Medubrigenses, Medobrigenses ou Meidobrigenses. A primeira forma encontra-se em Plínio, IV, 118. O De bello Alexandrino refere o ataque de Q. Cássio Longino a Medobriga. Uma inscrição do Museu de Lamego, procedente dos muros do castelo, regista uma Boutia, Meid(obrigensis ou ubrigensis) (Vaz, 1983: 9). Adoptemos a grafia Meidobriga para a capital deste populus, convertido em civitas.

Esta capital foi identificada por Russell Cortez (1953: 506) com o castro de Ranhados (Meda). Adriano Vasco Rodrigues (1983: 61) considerou o Castelo Velho do Vale da Manta (Meda) como «o núcleo principal da comunidade dos Meidubrigenses» mas não encontrou aí vestígios de romanização. A nossa proposta é a de identificar Meidobriga com a actual vila de Freixo de Numão, onde se têm feito ultimamente importantes achados (Coixão, 1996: 96-105)
O local do Castelo, na própria vila de Freixo de Numão, parece apropriado a um castro, pelo que podemos avançar, a título de hipótese, com a ideia de uma renovação urbana augustana (data possível da constituição da civitas) ou flaviana (data presumível da concessão do Ius Latii à civitas) do primitivo castro indígena.

A cerca de sete quilómetros para Noroeste, em Numão, ficava um vicus. Os vicani deixaram num rochedo a inscrição: As(s)anianc(enses) via $(m)$ fecerunt (Curado, 1985 [1]). Daqui deduzimos o nome do vicus: Assanianca. Não é possível dizer, por enquanto, se uma estrada ligava directamente Assanianca a Meidobriga.

Sensivelmente a mesma distância que decorre de Numão a Freixo de Numão é a que separa esta vila da Quinta das Olgas, agora para sudeste, quinta onde parece situar-se outro vicus (Coixão, 1996: 148). Ou ficaria este outro vicus na Quinta de Santa Maria da Ervamoira, em sítio sobranceiro ao Côa (Guimarães e Peixoto, 1988-1994)?

Maior é a distância que separa Freixo de Numão, 
de Longroiva, o próximo vicus a sul, conforme se deduz de uma ara aí achada e consagrada a Banda Longobricus (Curado, 1985).

Em Numão também se encontrou uma inscrição dedicada aos deuses e às deusas de Coniumbriga (CIL II 432; Etienne e Fabre, 1976: 21-22). Temos dúvidas se esta Coniumbriga se identifica com a Conimbriga a sul de Aeminium ou se trata de outra povoação do mesmo nome eventualmente existente na área dos Meidobrigenses. O dedicante, cavaleiro da terceira coorte lusitana (que serviu na Germânia), deve ter recebido a cidadania no tempo de Cláudio ou Nero, no termo do serviço militar, e ter-se-á fixado no vicus Assanianca. Mas, se era daqui natural, por que razão dedicou a ara aos deuses de $\mathrm{Co}$ niumbriga? Se era natural de Conimbriga, por que razão não voltou à cidade natal e se fixou em $\mathrm{Nu}$ mão?

É possível que Fernando Curado tenha razão o quando localiza uma Coniumbriga no Castelo Velho do Monte Meão, na freguesia de Vila Nova de Foz Côa (Curado, 1988-1994).

Sá Coixão tem realizado, na área do concelho de Vila Nova de Foz Côa (do qual Freixo de Numão é freguesia), uma importante e bem sucedida prospecção arqueológica que já se traduziu num livro (Coixão, 1996). O autor classifica as estações em villae rústicas e casais. Às primeiras preferimos chamar granjas. Na maior parte dos casos concordamos com a classificação feita por Sá Coixão, embora discordemos numa ou noutra identificação particular.

Vejamos como se apresenta o povoamento na área de Freixo de Numão. Dotámos as granjas de propriedades de 50 hectareś e os casais, de 5 hectares.

A área na mais imediata vizinhança de Freixo de Numão não tem vestígios de granjas nem de casais, sobretudo par nordeste e sudoeste. Os terrenos, porém, haviam der ser cultivados para abastecimento da cidade e são aliás irrigados por numerosas pequenas linhas de água. Estaria essa área dividida em pequenas propriedades agricultadas por moradores na cidade que diariamente (ou com frequência) se dirigiriam às suas courelas? Podemos facilmente imaginar mais de 300 hectares de terras agricultáveis que, divididas em parcelas de um ou dois hectares (ou ainda menos), representariam trabalho e sustento para mais de 200 fogos. Não ultrapassaria meia hora o caminho a pé até à mais distante dessas courelas.

De Freixo de Numão devia sair uma via para norte, direita ao Douro. Não temos estudo sobre o traçado dessa via, da qual todavia permanece um troço calçado junto a estação n. ${ }^{\circ} 109$ (Coixão, 1996: 134). O percurso que traçamos no nosso mapa é o suposto por Sá Coixão. Ao longo desta via temos um rosário de granjas e casais.

Começando de norte para sul, temos granjas nos n. ${ }^{\text {os }}$ 154, 66 e 31 . Na segunda, uma inscrição rupestre diz: Reburri P(ublii) Ortus (Encarnação, 1994: 218-220). Na área da primeira, a estação n. ${ }^{\circ} 32$ é talvez apenas um anexo ou instalação subsidiária.

Segue-se uma série de casais: n. $^{\text {os }} 74,61,10,16$, 91 e 106. O n. $^{\circ} 3$ parece corresponder a outra granja, que parece ter, no $n .^{\circ} 51$, um estabelecimento subsidiário, integrando uma forja.

No n. ${ }^{\circ} 8$ localiza Sá Coixão uma oficina de olaria. Seria autónoma ou dependente da granja $n .{ }^{\circ} 7$ ? Os n. ${ }^{\text {os }} 9$ e 6 (esta com um peso de lagar) corresponderão a outros casais?

As outras granjas da área, números 141, 13, 68 e 34, dispõem-se linearmente, de nascente para poente, ao longo da estrada moderna que, de Touça (a sul de Freixo de Numão), passando por Sebadelhe, se dirige a Horta (todas três, sedes de freguesia actuais). A via romana que havia de ligar a capital dos Meidobrigenses à dos Arabrigenses, a poente, capital esta cuja posição todavia por enquanto ignoramos, passava todavia mais a norte.

A estação $n .^{\circ} 5$, a mais importante da área, parece corresponder a uma villa. A negro representámos um fundus de 50 hectares e a tracejado um de cerca de 200 hectares. Admitimos facilmente que uma villa suburbana pudesse ter um fundus bastante menor que os 200 hectares atrás supostos para as villae.

No canto inferior esquerdo da nossa carta apresentamos um gráfico da área das quintas actuais vizinhas de Freixo de Numão, conforme dados amavelmente fornecidos por Sá Coixão: sete quintas andam pelos 10 a 25 hectares e oito, pelos 25 a 50 hectares. Como atrás dissemos, é nestes parâmetros que deve inscrever-se a propriedade romana que designamos por granja.

\section{O CASO DE EGITÂNIA (Fig. 2)}

O caso de Egitânia (Idanha-a-Velha) foi já por nós tratado (Alarcão, 1988), mas parece-nos útil reproduzir aqui o que dissemos naquele artigo. O panorama é de certo modo idêntico ao de Freixo de Numão, excepto que não se verifica zona vazia em torno da cidade: os casais e as granjas aproximamse da área urbana.

A prospecção arqueológica em torno de Egitânia foi feita por Pedro Carvalho, Luís Fernandes e José Ruivo, que apresentaram no $3 .^{\circ}$. Congresso Peninsular de História Antiga (1994), uma comunicação da qual, por enquanto, só existe síntese de pré-publi- 


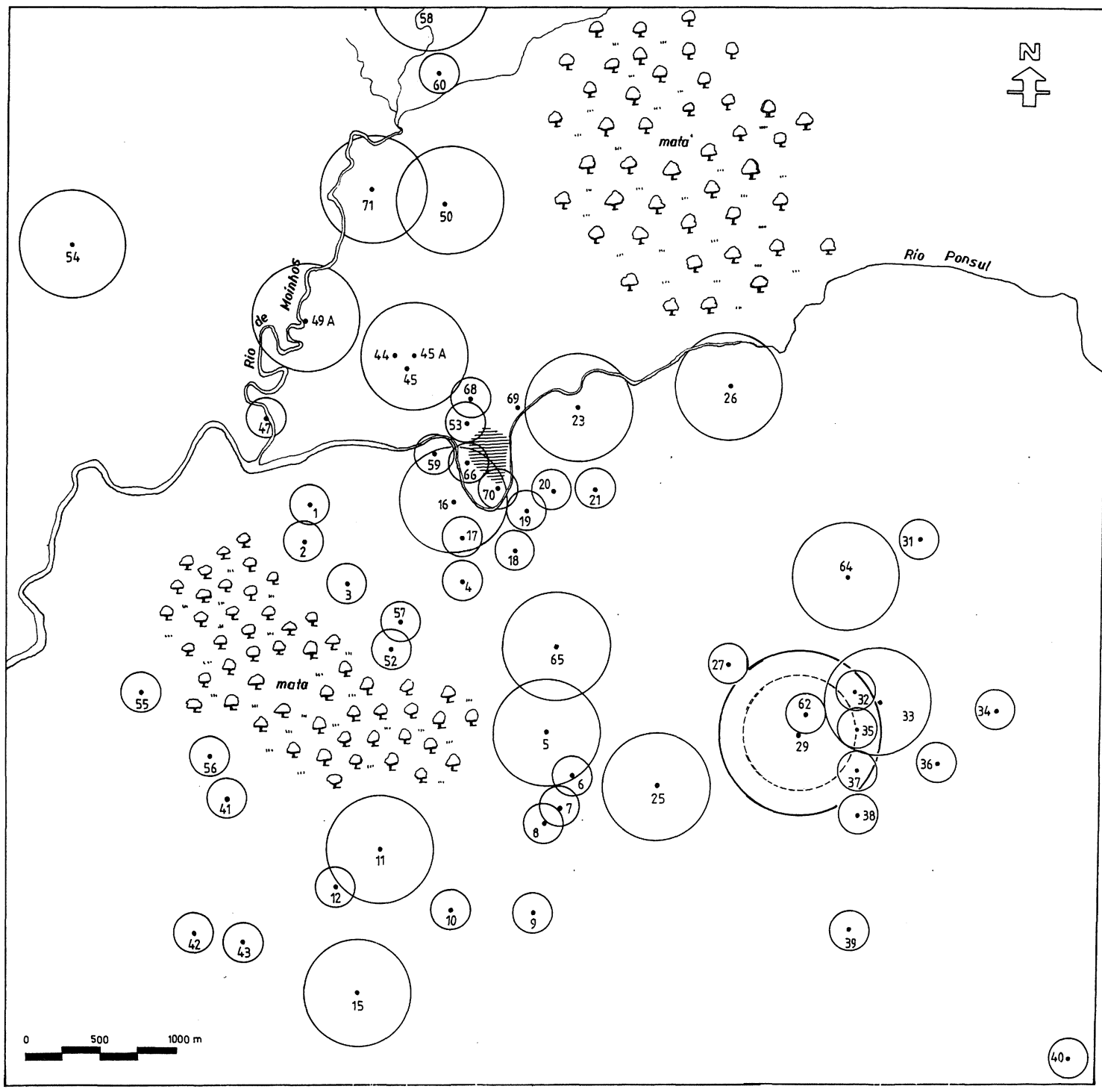

Fig. 2.-Arredores de Egitânia (Idanha-a-Velha).

cação. A prospecção foi realizada no âmbito do nosso seminário de Arqueologia e completada por Vitor Pedrosa, num outro trabalho de seminário (1996), inédito.

A nossa fig. 2 apresenta as estações localizadas pelos autores mencionados. De acordo com os parâmetros atrás apresentados, identificámos casais, granjas e uma villa; e dotámos os primeiros de propriedades da ordem dos 5 hectares; as granjas, de propriedades de 50 hectares; a villa, de um fundus de c. 100 hectares.

O panorama obtido é, pelo menos, credível. Perto da cidade observam-se cinco granjas e uma série de casais. Quatro destes (n. ${ }^{\text {ss }} 17,70,66$ e 59) caem dentro do hipotético fundus da granja n. ${ }^{\circ}$ 16: teria esta uma propriedade de 50 hectares, ou aqueles números correspondem, não a casais, mas a simples anexos da granja? O edifício correspondente ao sítio $n .^{\circ} 16$, onde D. Fernando de Almeida fez uma sondagem, tinha «un tanque circular em um possível pátio» (Almeida, 1977: 16). O autor classifica este sítio como villa. É também possível que se trate efectivamente de uma villa que, por muito próxima da cidade, teria um pequeno fundus.

Os sítios 53, 66 e 70 também poderão corresponder a necrópoles da cidade. Os sítios 19 a 20 são, na interpretação de Pedro de Carvalho, Luís Fernandes e José Ruivo, necrópoles da Egitânia. 
A estação n. ${ }^{\circ} 69$, a poente do n. ${ }^{\circ} 23$, tem $3.000 \mathrm{~m}^{2}$. De acordo com os nossos parâmetros, deveríamos fazer dela a sede de uma nova granja. A verdade é que, sendo vasta a área de dispersão dos achados, estes se reduzen a materiais cerâmicos de construção: não teremos aqui uma telharia, isto é, uma oficina para o fabrico de telhas e tijolos?

As estações n. ${ }^{\text {os }} 44$ e 45 seriam anexos da granja n. ${ }^{\circ} 45 \mathrm{~A}$, com $2.000 \mathrm{~m}^{2}$. No âmbito do fun$d u s$ desta granja insere-se um forno cerâmico escavado por Fernando de Almeida.

A villa $n .^{\circ} 29$, com $7.000 \mathrm{~m}^{2}$, incorpora, no seu hipotético fun$d u s$ de 100 hectares, várias pequenas estações em trono das quais traçámos círculos como se se tratasse de casais; mas não estaremos antes em presença de estabelecimentos anexos da villa?

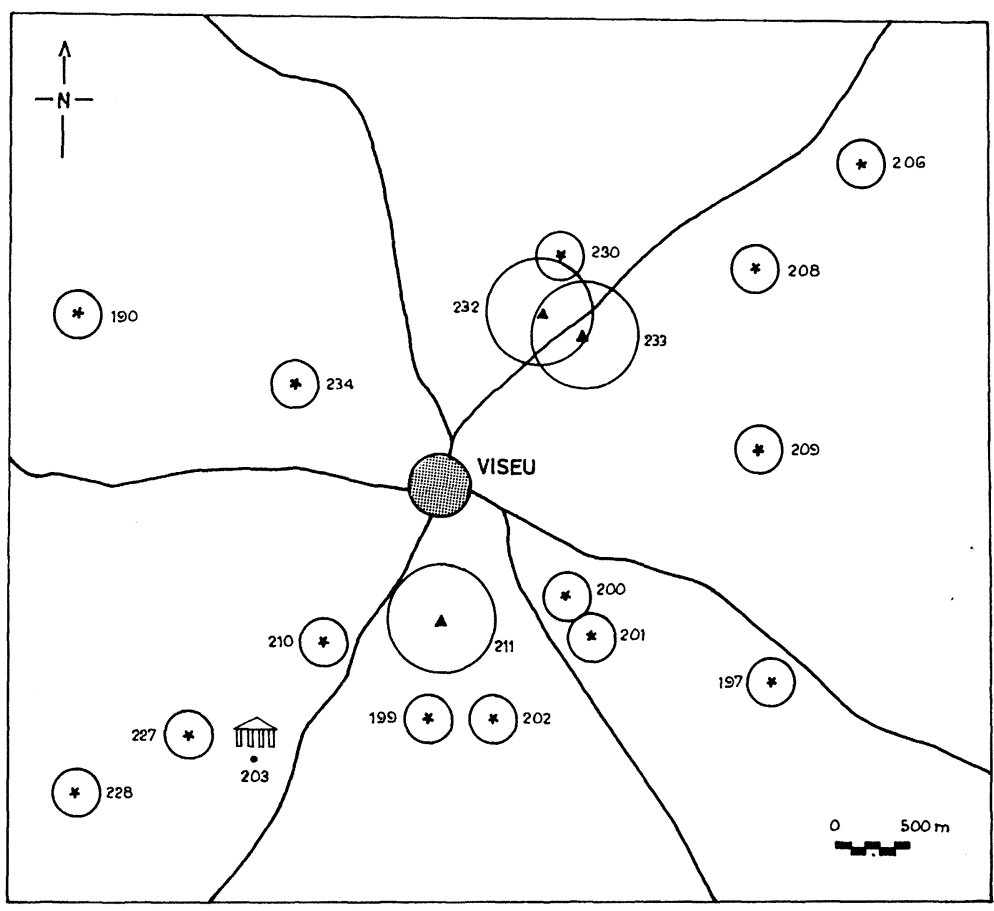

Fig. 3.-Arredores de Viseu.

paisagem em torno da Egitânia como uma série de casais que poderiam ter 5 hectares (ou um pouco mais) e de granjas de 50 hectares, com uma villa duvidosa de 100 hectares; não é visível, neste território, nenhuma villa de 200 hectares, o que não significa que propriedades desta dimensão não tenham existido noutras áreas da civitas egitaniense. Algumas áreas há tão sem nada de cacos que, olhando o vazio, nos lembramos poderem ter sido outrora pinhais ou azinhais, acudindo à necessidade que a cidade tinha de lenha. Infelizmente, não podemos traçar as vias que vinham desaguar à Egitânia e por onde avançavam, pesadolentos, os carros de bois carregados. A área nascente, entre os $n .^{\circ s} 23$ e 26 , por um lado, e os n. $.^{\text {s }} 65,27$ e 64 , por outro, não foi devidamente prospectada e talvez venham a encontrar-se aqui outras estações.

\section{O CASO DE VISEU (Fig. 3)}

Similar, se bem que menos denso, certamente por virtude de prospecção menos sistemática ou por desaparecimento dos vestígios numa área hoje densamente povoada, é o caso da zona envolvente de Viseu, tal como o podemos reconstituir a partir do trabalho de João Vaz (1997). Observemos a ausência de vestígios arqueológicos na periferia mais imediata de Viseu (aquela que podia alcançar-se em quinze 


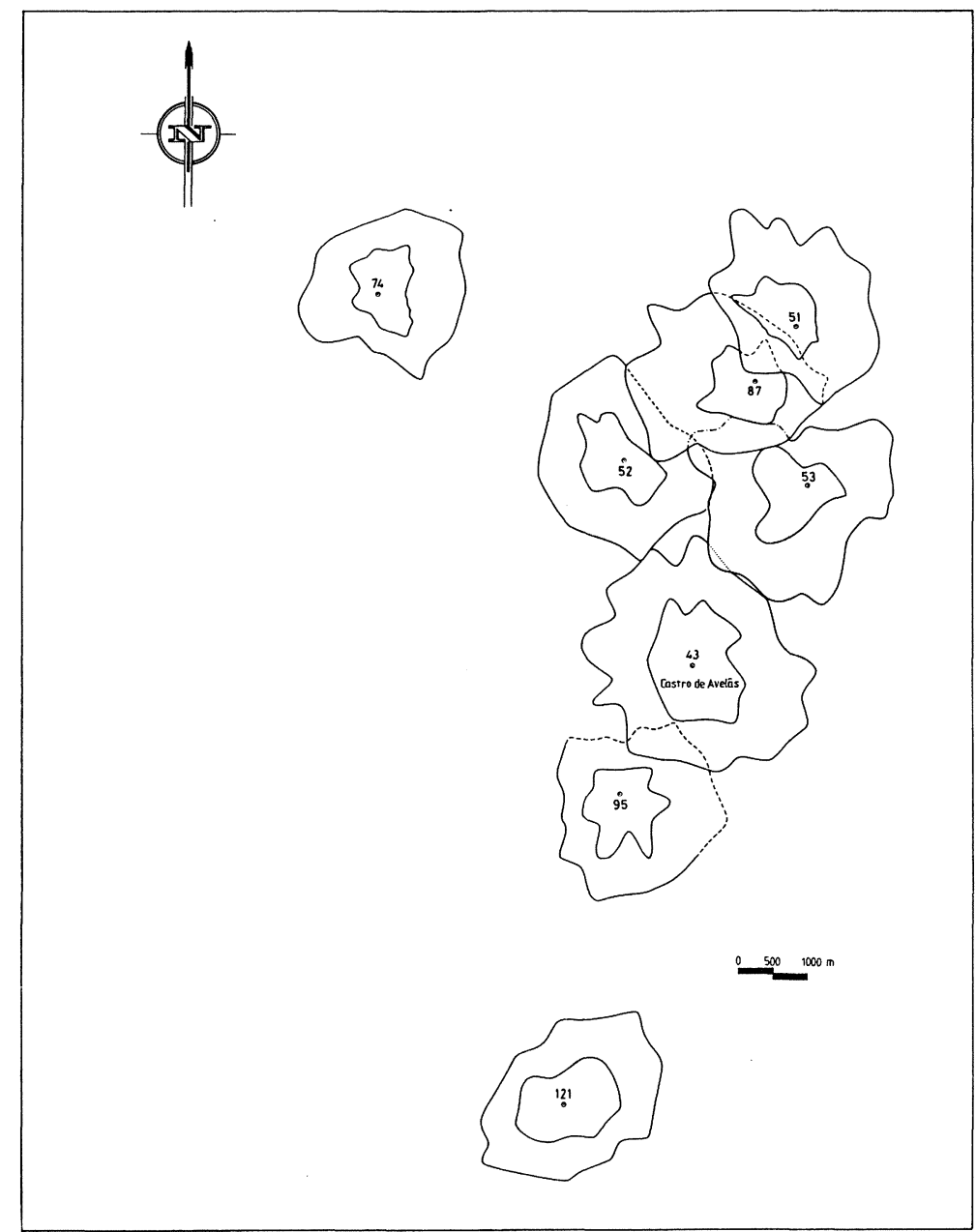

Fig. 4.-Aldeias dos arredores da civitas Zoelarum (Castro de Avelãs).

não observamos nem casais, nem granjas, nem villae em torno de Castro de Avelãs. Aliás, a forma típica de povoamento da parte oriental da nossa província de Trás-os-Montes parece ter sido a aldeia.

De acordo com Sande Lemos, são aldeias que se observam nas vizinhanças da capital da civitas Zoelarum: de norte para sul, os n. ${ }^{\text {os }} 74,51,87,52,53$ e 95; mais distante, a sul, a aldeia n. ${ }^{\circ} 121$. Marcámos também os territórios de quinze e trinta minutos das aldeias. Há uma certa sobreposição dos territórios dos n. ${ }^{\text {os }} 51,87,52$ e 53 .

A dimensão média dos territórios de trinta minutos é de cerca de 500 hectares. Ainda hoje, no Barroso, o termo das aldeias não ultrapassa geralmente um raio de $1.350 \mathrm{~m}$ (Lema, 1978: 80), perfeitamente praticável em meia hora. Em 1572, o termo de Vilaça (Montalegre) não ultrapassava os $1.400 \mathrm{~m}$ (Freund, 1974). Uma grande parte das terras do termo seria constituída por matos e pastos. No concelho de Montalegre, há poucos anos, matas e pastos representavam $70 \%$ do termo das aldeias e as terras cultivadas, $30 \%$ (Lema, 1978: 48);

minutos andando a pé a partir da cidade) e um certo número de granjas e de casais a maior distância da cidade. Duas granjas interferem uma com a outra: os n. ${ }^{\text {ss }} 232$ e 233 . Mas, obviamente, os círculos que lhes definimos como prédios rústicos são hipotéticos.

Caso curioso é o da aparente existência de um templo consagrado à divindade indígena Albucelaincus Efficax a cerca de meia hora de caminho da cidade (n. ${ }^{\circ}$ 203).

\section{O CASO DA CIVITAS ZOELARUM} (Fig. 4)

A capital da civitas Zoelarum situava-se em Castro de Avelãs (Lemos, 1993, com bibliografia). Assinalámos na nossa carta os territórios de quinze e de trinta minutos em torno do oppidum.

Ao contrário de Freixo de Numão e de Egitânia, por seu lado, os prédios rústicos, no mesmo concelho, eram geralmente inferiores a 3 hectares (Lema, 1978: 54).

Se o termo das aldeias romanas fosse, em média, de 500 hectares e se apenas $30 \%$ das terras fossem cultivadas, teríamos 150 hectares de terras aráveis, o que, dividido por 10 fogos, daria 15 hectares a cada um; e, dividido por 15 fogos, 10 hectares. Mas, possivelmente, cada família tinha menos do que isso. É possível que o termo das aldeias romanas fosse inferior a meia hora de marcha, o que resolveria o problema da sobreposição dos $n{ }^{\circ}{ }^{\text {s }} 51,87,52$ e 53 .

\section{O CASO DE PAX IULIA}

O território de Pax Iulia (Beja) foi centuriado em lotes de 200 jugera ou 50 hectares (Mantas, 
1996). Aparentemente cada família recebeu quatro lotes, isto é, 200 hectares. A prospecção que está a ser conduzida por Maria da Conceição Lopes está a encontrar uma villa por cada 200 hectares.

O panorama dos arredores de Pax Iulia, que se repetiria em Ebora Liberalitas Iulia (Évora) e nas cidades cujos territórios foram centuriados, era, assim, muito diferente dos casos anteriormente considerados: nem aldeias, como no caso da civitas Zoelarum, nem casais e granjas, como no caso de Freixo de Numão, mas um território regularmente cadastrado, com uma villa em cada lote.

\section{CONCLUSÃO}

O povoamento romano no raio mais próximo das cidades capitais de civitates manifesta uma certa diversidade em Portugal, diversidade que não parece poder explicar-se por razões geomorfológicas ou edafológicas, antes por razões sociais e económicas.

A aldeia, a norte do Douro, na parte ocidental do conventus Asturicensis, corresponde a uma estrutura social de gente modesta mas ligada por vínculos muito sólidos de solidariedade social, talvez com formas de propriedade comunal: é a área das gentilitates que perduraram, como é sabido, até ao Baixo-Império.

As granjas e os casais na periferia das cidades revelam a ausência de comunitarismo e uma classe de pequenos proprietários rurais. Estes não existiriam naquelas outras cidades, como Pax Iulia, cujos territórios foram centuriados. Nestas, os proprietários rurais eram todos abastados e uma grande parte da população livre, sem bens fundiários, viveria integrada nas familiae rusticae dos donos das villae.

Os núcleos urbanos das civitates com pequenos proprietários rurais seriam muito menores, em superfície, do que os núcleos das civitates com grandes propietários; nestas últimas, devemos possivelmente supor uma classe numerosa de artesãos e pequenos comerciantes que as cidades menores, como Freixo de Numão (Medobriga?), Egitania ou Viseu não sustentariam.

\section{REFERÊNCIAS}

AlarÇão, Jorge de (1998): «A paisagem rural romana e alto-medieval em Portugal», Conimbriga, 37.
CoIXão, António do Nascimento Sá (1996): Carta arqueológica do concelho de Vila Nova de Foz Côa, Vila Nova de Foz Côa.

Cortez, F. Russell (1953): «A localização dos Meidobrigenses», Zephyrus, 4: 503-506.

Curado, Fernando Patrício (1985): «Ara votiva de Longroiva (Meda)», Ficheiro Epigráfico, 11, n. ${ }^{\circ} 44$.

Curado, Fernando Patrício (1985 [1]): «Incrição rupestre de Numão (Vila Nova de Foz Côa)», Ficheiro Epigráfico, 11, n. $^{\circ} 48$.

Curado, Fernando Patrício (1988-1994): «A propósito de Conimbriga e de Coniumbriga», Gaya, 6: 213-234.

ENCARNAÇão, José d' (1994): «Apostillas epigráficas», Humanitas, 46: 217-230.

Étienne, R. e Fabre, G. (1976): Fouilles de Conimbriga. II. Épigraphie et sculpture, Paris.

FREUND, Bodo (1974): «L'ancien cadastre de Vilaça. Étude méthodique sur l'évolution d'un village du nord du Portugal», Finisterra, 9(17): 51-74.

Guimarães, Gonçalves e Peixoto, M..$^{\mathrm{a}}$ da Graça (1988-1994): «A estação arqueológica da Quinta de Santa Maria da Ervamoira-Muxagata, Vila Nova de Foz Côa (Notícia preliminar)», Gaya, 6: 235-262.

Lema, Paula Bordalo (1978): Tourém. Uma aldeia raiana do Barroso, Lisboa.

Lemos, Francisco de Sande (1993): Povoamento romano de Trás-os-Montes oriental, Braga (tese de doutoramento, policopiada, apresentada à Universidade do Minho).

Mantas, Vasco (1996): «Teledetecção, cidade e território: Pax Iulia», Arquivo de Beja, série III, 1: 5-30.

Martins, Manuela (1990): O povoamento proto-histórico e a romanização da bacia do curso médio do Cávado, Braga.

Quintela, António de Carvalho; CARdoso, João Luís; Mascarenhas, José Manuel (1995): «Barragens romanas do distrito de Castelo Branco e barragem de Alferrarede», Conimbriga, 34: 45127.

Rodrigues, Adriano Vasco (1983): Terras da Meda. Natureza e cultura, Meda.

VAZ, João L. Inês (1983): Inscrições romanas de Lamego, Lamego.

VAZ, João L. Inês (1997): A civitas de Viseu. Espaço e sociedade, Coimbra. 